\title{
LOURDES ESPÍNOLA E A POESIA PARAGUAIA CONTEMPORÂNEA
}

\author{
Joyce Luciane Correia Muzi ${ }^{1}$
}

\section{Resumo}

Neste artigo apresentamos a poeta paraguaia Lourdes Espínola como um dos nomes da literatura contemporânea latino-americana. Nosso intuito é contextualizar o país em que se insere sua obra, bem como a vida da autora, para em seguida apresentar brevemente sua obra poética, evidenciando a utilização dos símbolos recorrente em seus poemas.

Palavras-chave: Poesia. Paraguai. Lourdes Espínola. Símbolo.

\begin{abstract}
This article presents the Paraguayan poet Lourdes Espínola as one of the names of contemporary Latin American literature. Our aim is to contextualize the country in which her work appears, as well as the author's life, then to present a brief summary of her poetic work, demonstrating the use of symbols which recurs in her poems.
\end{abstract}

Keywords: Poetry. Paraguay. Lourdes Espínola. Symbol.

\section{Introdução}

Se olharmos para a história do povo paraguaio e nos aproximarmos do que foi a maior guerra que o país já teve, perceberemos o quão ficou marcado este povo. A Guerra da Tríplice Aliança, que, ironicamente, nas escolas pelo Brasil afora insistimos em chamar Guerra do Paraguai, teve ocultações que acabam por manter longe até hoje o país fronteiriço. Não obstante, para quem tem a sorte de acercar-se desse país, pode compreender os reflexos dessa história em sua produção artística.

Estamos diante de uma sociedade que ficou despedaçada após uma grande guerra na segunda metade do século XIX - na opinião de muitos, a maior e mais triste de todos os tempos - e que só se levantou graças à ação das mulheres, que atuaram como agricultoras, comerciantes, industriais, enfim, que tomaram a linha de frente da sociedade paraguaia pósguerra - os homens que restaram, um número irrisório, eram meninos e anciãos. As mulheres paraguaias tiveram a triste empresa de ressuscitar uma nação despedaçada. Após décadas do

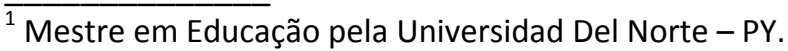
Mestre em Tecnologia pela UTFPR

Professora da Área de Linguagens, Códigos e suas Tecnologias do Instituto Federal do Paraná - IFPR - Campus Paranaguá-PR, Brasil. E-mail joycemuzi@yahoo.com.br
} 
início deste recomeço, vemos que a força feminina permanece. Na política, na educação, na literatura são vários os nomes que se destacam - elas são herdeiras de uma luta coletiva pela reconstrução de um país. É sobre a trajetória de uma dessas mulheres que já não precisa lutar com armas que trataremos neste artigo.

\section{A poesia paraguaia em foco: Lourdes Espínola}

Muito se ouve a respeito de nosso vizinho. Especialmente os que vivemos ao lado, no Paraná, ouvimos muito sobre sua economia, seus acordos políticos, enfim, o que a mídia nos oferece. Mas, em se tratando de nomes da literatura paraguaia, mesmo nós, profissionais e estudantes das Letras, saberíamos citar um ou dois, e talvez nenhum deles seja do sexo feminino.

Quando se fala de literatura paraguaia alguns poucos nomes nos vêm à mente, ainda que seja um país vizinho - Augusto Roa Bastos é o mais famoso deles. O que Miguel Ángel Fernández Argüello chamou “omissões, equívocos e ocultações” acabou por determinar o que se conhece por literatura feita no Paraguai: muito pouco, quase nada.

Infelizmente são raros os esforços em favor dos que ainda estão entre nós. Na maioria das vezes, o esforço é um pouco maior para recuperar e valorizar personalidades que já morreram, como é o caso de Rafael Barrett, recuperado por Argüello (2008). O escritor, ainda que espanhol de nascimento, foi nome importante no início do século XX como retratista literário das agruras de um povo que foi escravizado no campo, com sua obra El dolor paraguayo. Além dele, Argüello (2008) "recupera” o nome de uma mulher - Carmen Soler. Segundo ele, ela teria sofrido, devido à desinformação de alguns, a exclusão do cânone: sua poesia social e política não teve ecos retumbantes. O valor de Carmen Soler e Rafael Barrett, na história mais recente do Paraguai, está sendo aos poucos recuperado, entretanto outros tantos ficaram para trás. Escritores, jornalistas, narradores, enfim, vozes de inspiração ímpar permanecem esquecidas ou pouco lembradas. É claro que isso não é um privilégio do Paraguai, já que isso pode acontecer em quaisquer outros países do mundo. No entanto, aqui nos preocuparemos em trazer ao público a obra de uma mulher de bastante força e valor literário, justamente por entendermos como indispensável tratar de registrar os nomes contemporâneos da literatura latino-americana.

Mar Langa Pizarro escreveu que uma das formas de conhecer o imaginário de um povo é aproximar-se de suas expressões artísticas. Por isso apresentamos um nome que se 
destaca na expressão poética contemporânea nas terras paraguaias: Lourdes Espínola. Diplomata, professora universitária, crítica literária e jornalista cultural, poeta, mas, antes de tudo, mulher. E, apesar de toda formação e bagagem cultural, o que nos salta aos olhos quando lemos um de seus poemas é o ser mulher, pela condição declarada de voz engajada que fala de dentro da situação: é uma mulher que viveu e vive dentro de uma sociedade que, após um longo período ditatorial e patriarcal, que só se equilibrou graças ao trabalho das mulheres, soube se mostrar parte de um todo que representa muito da identidade da mulher paraguaia atual. Por meio de seu discurso literário e crítico, Lourdes Espínola demonstra sua consciência histórica da condição da mulher durante os anos de reestabelecimento do país, após sua derrota na Guerra da Tríplice Aliança até os dias atuais, estabelecendo-se como um nome que merece ser lembrado.

A trajetória de vida assim como da poesia de Lourdes Espínola é bastante interessante e nos incita a questionar: quantos e quantas estarão também “escondidos” dos holofotes, ofuscados e velados, longe dos olhos dos grandes públicos?

Lourdes Espínola nasceu em Assunção em 9 de fevereiro de 1954. Formou-se em Odontologia, Biologia e Letras, além de ter obtido vários títulos em instituições nos Estados Unidos e Europa. Ainda que sua formação surpreenda pelo número de títulos obtidos (vários "Masters”, que correspondem ao nosso Mestrado, e Doutoramentos), o que chama atenção em sua obra é a simplicidade de expressão de seu ser mulher e da sua necessidade de exprimir-se pela poesia: "Y ser y no. Ser mujer,/ con manuscritos de internas visiones/ nombrando la experiencia.” ${ }^{1}$ E essa experiência vemos refletida no uso dos símbolos que ela naturalmente empresta da biologia, sua primeira formação. Seria esta a explicação para sua atração por corpos que veremos em sua produção mais recente? Atrevemo-nos a dizer que não.

Filha de Elsa Wiezell, também poeta, Lourdes começou sua trajetória cedo, escrevendo ensaios e contos sobre aspectos sociais, direitos humanos e a situação da mulher, mas foi com a poesia que encontrou seu ponto alto. Em 1973 ela lança o livro de poemas Visión del Arcángel en once puertas, inspirado na inefável A Divina Comédia, de Dante Alighieri. Segundo a própria autora, sua preocupação era pela forma e cada porta vai representar "[...] una diferente devastación social y humana que se abre, casi como un paralelo a los círculos del infierno de Dante” (ESPÍNOLA, 2004, p. 605). O Arcanjo: o poeta humano e espiritual. Nos versos finais:

Es necesario que me envuelva, Que me entregue al abismo 


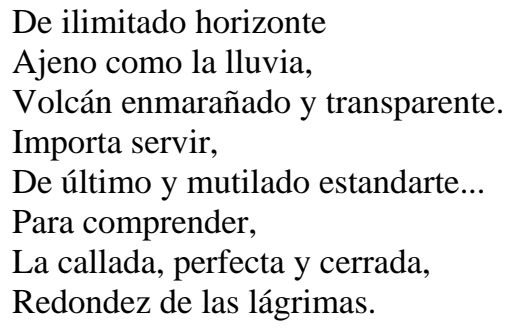

Não é possível ler seus poemas sem considerar que as imagens e os símbolos têm presença constante. Nesse sentido interessam-nos algumas considerações. Para Alfredo Bosi é próprio da poesia a capacidade de suscitar imagens, que mantêm relação com a sensação visual. Para o autor “A imagem nunca é um ‘elemento’: tem um passado que a constitui; e um presente que a mantém viva e que permite a sua recorrência” (BOSI, 1990, p. 15-16). Além disso, para ele a imagem é resultado de forças instintivas transformadas. Interessa-nos o seu questionamento: “O que é uma imagem-no-poema? Já não é, evidentemente, um ícone do objeto que se fixou na retina; nem um fantasma produzido na hora do devaneio: é uma palavra articulada” (BOSI, 1990, p. 21). Esta palavra recupera elementos essenciais à significação os símbolos, e sua função simbólica (CIRLOT, 2007). No dicionário, símbolo aparece como aquilo que, por princípio de analogia, representa ou substitui algo ou ainda aquilo que evoca, representa ou mesmo substitui algo vago ou mesmo ausente (FERREIRA, 1999). JuanEduardo Cirlot (2005) nos sugere que os símbolos não se encontram isolados, eles buscam unir-se, e representam de tal maneira aquilo que o/a poeta busca exprimir que chegam a criar uma mitologia. É nesse sentido que podemos tratar a obra de Lourdes Espínola como um emaranhado de símbolos que apontam para sentidos em torno do seu ser mulher no mundo, como mulher, escritora, representante de uma geração oriunda de lutas e mudanças em todos os âmbitos.

Com base no exposto, podemos citar o segundo livro da poeta. Em Monocorde amarillo (1976), os símbolos são mais fortes que no primeiro e já transmitem o que está por vir. Um poema longo, dividido dessa vez em acordes para tratar da criação - um só Criador, representado pelo Monocorde, e o Sol, astro máximo que gera a vida. A referência ao sol, nas palavras de Diel (apud CIRLOT, 2007), recupera o espiritual, já tratado nas referências à tríade dantesca, e o intuitivo e com isso aquilo ela pretende fazer com que voltemos nosso olhar para um determinado lugar e vejamos possibilidades: "Para que nazcas y renazcas para volver a conocer",2, "Apúrate, no hay tiempo [...]”3, num esforço em abrir nossos olhos, ouvidos, corpos para os acordes de sua poesia. 
Também em seu terceiro livro, de um ano depois, Almenas del Silencio, ela está preocupada com o ser e a essência. Para tratar do tema, divide o livro em quatro partes: Conhecimento, Descobrimento, Criação, Verbo. Segundo a autora, neste começará a desenvolver uma combinação que chegará até os livros mais recentes: a paixão e o ofício de escrever.

\author{
Acepto como don natural \\ Esa coordenada de imágenes. \\ Esta desaforada \\ Rima verbal de símbolos de verso. \\ Este desenfreno de nacer jadeante \\ En la inutilidad de lo bellamente sonoro. \\ En la transfiguración \\ Del absurdo de vida \\ Por creer aún \\ Que vale la pena ser poeta.
}

As imagens lhe surgem naturalmente num dos momentos mais “metalinguísticos” de sua produção poética.

Em 1985 acontece um fato bastante importante em sua trajetória - seu livro seguinte sai em edição bilíngue nos Estados Unidos: Ser mulher y otras desventuras/womanhood and other misfortunes. Esse é um livro importante porque neste momento sua voz começa a se configurar. Ela diz sentir “[...] el encuentro de una voz muy propia y personal” (ESPÍNOLA, 2004, p. 610). Sua perspectiva vai sofrer modificações, já que não está em sua terra natal quando o escreve, e essa distância, cultural e linguística, transforma sua escritura; ela fala de limpeza, ficar com o essencial, não se deixar levar pela forma (ESPÍNOLA, 2004). É um momento decisivo, pois ela descobre um território seguro ao qual ela pode recorrer em todos os momentos: o corpo. Neste momento a simbologia ligada ao corpo e seu aspecto externo, representado pelas vestimentas, ou seu aspecto fisiológico, representado por exemplo pelos tímpanos e pela boca, vão se cruzar e se unir para que as imagens surtam um efeito de unidade do corpo de uma mulher (o interno e o externo).

O estar longe de casa, o encontrar-se em si mesma e o contato com o pensamento feminista dos anos 80 serão elementos essenciais para a seleção dos símbolos nessa nova fase. Além disso, sua preocupação se voltará para destacar-se como parte de uma cultura marcadamente feminina:

La alternativa:

Saltar del balcón, despedazarlo.

Faldas, abanico, hilo, aguja:

Me desnudo y rebelo.

¡Basta de mirar la vida 
desde este balcón!

Cárcel semicircular

Tímpano sordo, sorda boca

Digo y grito

Del solitario oficio de escribir.

Manuscrito de internas visiones

Espejos de mujer abriéndose.

Nazco

Rompiendo venenosos manantiales.

Delmira

A Delmira Agustini

Contradicción o ser mujer

Es todo uno,

Arder

Fingir pudor

Callar, cantar

Adorar el propio cuerpo

Engañarlo con trajes

Potes, perfumes y artificios

Todo envuelto en la pretendida modestia.

$[\ldots]^{4}$

Percebe-se que ela aproveita o momento para desgarrar-se, para sair de um estado de letargia e assumir o controle de suas ações - e escrevendo ela estaria renascendo, e nesse sentido ela representa outras mulheres. É o que sugere Sharon Keefe Ugalde, crítica norteamericana responsável pelo prólogo desse livro: "Muchos poemas están enraizados, no en las circunstancias de la historia individual de la existencia de la poeta, sino en la situación colectiva de la mujer en una sociedad dominada por el hombre” (ESPÍNOLA, 2004, p. 611). O destaque da crítica vai para o seu engajamento e para o silêncio da poeta: silêncio que ilustra anos de silenciamento de milhares de mulheres.

Ser mulher e outras desventuras é sinônimo de descobrir-se dentro de si própria como um novo ser, uma nova mulher, já que a anterior não serve mais:

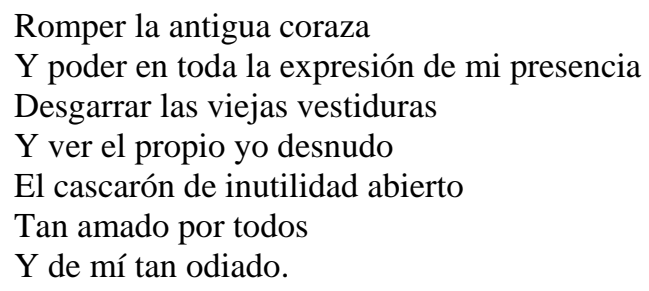

A temática é retomada no livro de 1986 - Tímpano y Silencio: o conflito entre o que ela é e o que ela parece ser. Os símbolos emprestados da natureza de novo lhe servem para criar as imagens: "Desde el útero grito”, “Con pequeñas uñas trate / De rasgar el útero, / Desbordar el agua protectora y tibia”. Segundo Cirlot (2005, p. 48) nestes versos podemos ver uma série: uma combinação que objetiva "uma mitologia que tende para o símbolo 
principal”, que neste caso é o corpo feminino. Útero, unhas, “água” que protege o feto representam o corpo feminino. Essa representação do útero, como espaço de falsa proteção que se pretende por analogia do universo doméstico reservado às mulheres, é derivada de sua influência do feminismo francês. É possível encontrarmos alguns poemas, dentre os seus quase 50, que remetem a conceitos de $O$ segundo sexo de Simone de Beauvoir.

Outro símbolo importante nessa obra é o espelho. Segundo Cirlot (2005), tal como a água que pode refletir imagens, assim como no mito de Narciso, pelo espelho é possível que se veja um reflexo de uma mulher que por ser mulher, durante centenas de anos, foi representada pelo olhar do outro. A mulher representada seria uma imagem “[...] afogada y amortajada con igualdad escondida desde siglos” (ESPÍNOLA, 2004, p. 613).

Já nos anos 90, Lourdes lança Partidas y Regresos que tem o privilégio de ser prologado por Augusto Roa Bastos, que diz:

De esta ausencia-presencia brota la melodía vital y elegíaca de estos poemas. Acaso el triunfo de lo erótico en esta poesía lúcida y despojada consiste en afirmarse en la deseada como imposible conciencia de eternidad de lo efímero. Hacer voz y canción del amor que resucita su propia resurrección a cada partida, a cada regreso (ESPÍNOLA, 2004, p. 614).

Seu compromisso com a poesia se pode notar em trechos como:

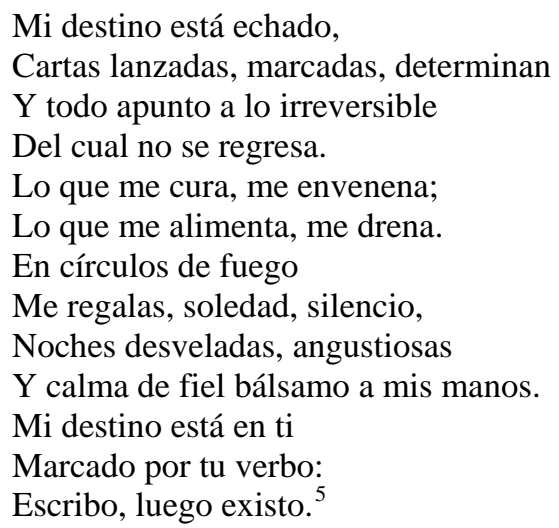

E o espelho reaparece para construir uma nova imagem; ao lado de máscaras que, ao contrário do espelho que revela, escondem, camuflam, escamoteiam - real e irreal, claro e escuro, aquilo que ela imagina e o que ela esconde, frente a frente:

Hay máscaras y espejos,

Máscaras para el amante de paso

Que deseamos no se quede,

Máscaras que dan poder

Y nos defienden.

Pero están los espejos

Que devuelven al otro en el salto, 
Espejos para el amor esperanzado

Y para ocultar la muerte. ${ }^{6}$

Em La estrategia del caracol, de 1995, os símbolos continuam a ser evocados; permanecem numa linha mais imaginativa e contemplativa, daquilo que Rubén Bareiro Saguier, no Prólogo, vai chamar de “dimensión de la plenitud femenina”:

Siempre dije [...] que Lourdes es una de nuestras escritoras que, en forma
coherente, asume la feminidad, no como reivindicación feminista - o no solamente-,
sino como una manifestación sincera del impulso amoroso, del fuego sensual,
trasvasados con honda y precisa intensidad en su poesía (ESPÍNOLA, 1995, p. 2).

Mas sua força se faz mais presente quando utiliza elementos como em "Y ellos estaban también allí”, em que sua voz é a voz de vários ao mesmo tempo. Seu discurso está mais dinâmico, com imagens que se complementam, como flashes de um filme só. Um encadeamento invocado pela imagem de um caracol, cuja representação remete a uma espiral, que para Bosi (1977) representa a regularidade de um poema, e Lourdes Espínola utiliza para chamar atenção a um tema central para o qual se volta: a mulher.

A presença de títulos, fato inusual, está neste campo semântico: "Escribo letra de mujer”, “Escribo vida de mujer”, “Ser mujer”, “Destino de Poeta”, “Soy mujer, desobedezco".

O livro que sairá dois anos depois já é o oitavo de sua trajetória. Também em edição bilíngue, mas agora em espanhol/francês Encre de femme/Tinta de mujer. Lourdes adentra a Europa "pela porta da frente" 7 .

Palavras del Cuerpo, de 2001, traz como símbolo a água que, por seu caráter natural circular indo do céu à terra via precipitação (CIRLOT, 2005), serve tanto para sugerir movimento como a umidade aos corpos - corpos de homens e de mulheres apaixonados. Essa representação e seu tom passional podem ser vistos nos versos abaixo:

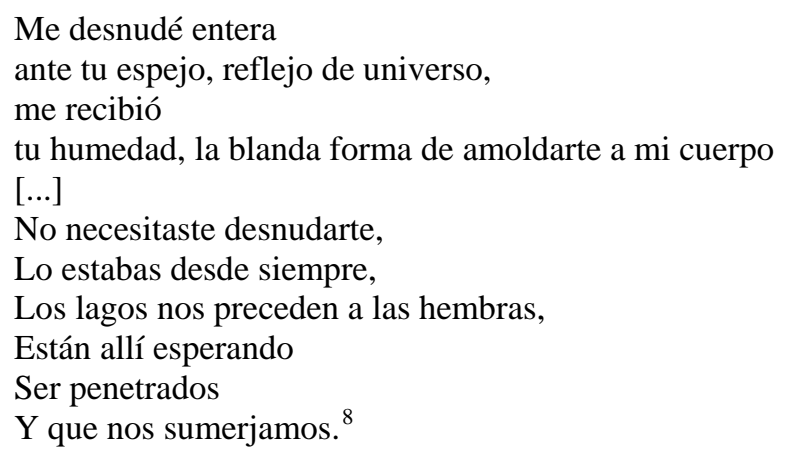


Para o professor Marini Palmieri, o simbolismo explorado pela poeta põe em destaque “el rito místico que reúne Eros y poesia [...]” (MARINI apud ESPÍNOLA, 2004, p. 620).

Ainda que de maneira breve, evidencia-se que sua trajetória já pode ser chamada longa. Poderíamos resumi-la com duas palavras: verdade e força. A verdade se manifesta a partir dos símbolos que são capazes de despertar comoção. Mais do que representações, são traduções de tudo o que nos rodeia silenciosamente. A força dos elementos utilizados podemos encontrar em textos como "La vida es una metáfora”, em que um certo pessimismo tenta emergir, mas que acaba sufocado por um cenário de segurança: “[...] vuelvo al mapa seguro de tu mano"9.

Ainda citaremos um último título que acreditamos ser o fechamento de um ciclo. Em As núpcias silenciosas (2006), surge a força a que nos referimos; neste a poeta apresenta uma coletânea de seus símbolos cada vez mais sutis e mais instigantes. O livro, em edição portuguesa, está estruturado a partir do título de cinco de seus livros anteriores: Ser mulher e outras desventuras, Tímpano e silêncio, Partidas e regressos, A estratégia do caracol e As palavras do corpo.

É um retorno a todas as imagens já exploradas. Mas não é um mero dizer de novo: é fazer-se mais forte pela repetição e a possibilidade de dar impulso novamente à comoção. Toda sua obra aponta para uma divisão em dois que sempre esteve em seus textos: a representação de dicotomias (partidas e regressos, a linearidade e o “caracol”), a representação dos corpos por dentro e por fora, realidade e ilusão, espelhos e máscaras e metapoesia.

(DE COMO AS MULHERES ESCREVEM POEMAS ERÓTICOS)

Se escrevesse um poema sobre nós, seria censurada.

Deixa-me então contar-te

como o junco se faz cana

e espalha lá dentro o seu mel oculto.

Ou falar-te daquela orquídea violeta

de pétalas e pétalas que navegam em seiva,

ou de como ela se abre

e entram estrelas

que iluminam o sangue, esse que estava adormecido.

E de como os olhos bebem

o dicionário todo.

Mas façamos um contrato:

a ninguém o contemos

para que este poema não morra censurado. 
A viagem da minha vida: suficientemente fechada para me proteger, suficientemente porosa para que tu penetres...

II

\begin{abstract}
A minha roupa virada do avesso, com as costuras à mostra: pequenas cicatrizes do meu corpo. Procurar equilibrar um anjo nas tuas longas pernas, é assim que me tens... e manténs.
\end{abstract}

III

A lua foi um presente poeirento - perfeito e único que tinha que devolver no dia seguinte: dependurei-a, pontual, polida, clara, dançando na ponta dum fio transparente.

Este último poema é um exemplo de como seus poemas representam a poesia paraguaia contemporânea. O que nos reserva sua obra: restaurar a literatura - é disso que precisamos. E se ainda restar uma última pergunta a respeito do símbolo mais evocado por ela: por que falar do corpo a partir de seu próprio corpo? A resposta pode ser dada por Carla Férnandes, professora e crítica francesa:

El punto de confluencia entre la teoría y la estética inherentes a la obra de Lourdes Espínola es el cuerpo, este espacio todavía no contaminado por la estética patriarcal. En ambos elementos radica la base social y comprometida de su poesía que se transforma en estética y poética de la creación, de la producción en verso mediante una reapropiación del cuerpo. Los medios de dominación (que tienen siempre que ver con el cuerpo femenino) pasan a ser en su obra medios de expresión (FERNÁNDES apud ESPÍNOLA, 2004, p. 614).

Este espaço ora dominado por outrem é reapropriado e ressurge como espaço de manifestação criativa e única de milhares de silenciadas, pela veia poética e criativa de Lourdes Espínola. 


\section{Algumas considerações}

É interessante que tenhamos a oportunidade de conhecer a obra da poeta paraguaia Lourdes Espínola, já que muito pouco da literatura daquele país chega até nós. Entendemos que muitos dos sentimentos expressos em seus versos representam mais do que sentimentos individuais. Ela própria, quando questionada a respeito de sua regionalidade, assume manter a capital Assunção e o país em muitos de seus poemas e especialmente em seu coração, mas ela está aberta ao universal - quer representar muito mais e alcançar outros corações além dos paraguaios: «a minha poesia é extra-territorial, universal» ${ }^{2}$.

Já é possível encontrar em sites destinados à divulgação da poesia ibero-americana ou latino-americana inúmeros poemas da autora, bem como breves biografias para justificar sua trajetória literária.

Atualmente, além de catedrática na Universidad del Norte, uma das instituições privadas mais conceituadas do Paraguai, com sede em Assunção, ela é correspondente da revista Nuestra América, presidenta da Escritoras Paraguaias Associadas (EPA), e membro da Comissão Nacional Bicentenário.

Por fim, destacamos as palabras de Heléne Cixous, importante nome da literatura feminista, para quem "La mujer debe inscribirse, debe escribir acerca de la mujer y traer a la mujer a la escritura, de donde le han echado tan violentamente como de su propio cuerpo" (CIXOUS apud ESPÍNOLA, 2004, p. 610). Nesse momento esperamos ter cumprido esse papel de tratar da escritura de uma mulher que ao propagar suas ideias e pensamentos revela sua imensidão íntima e busca representar ideias e pensamentos de muitas outras mulheres, sejam quais forem suas nacionalidades.

\footnotetext{
1 Do poema In Memorian a Sor Juana Inés de la Cruz. Disponível em http://www.lospoetas.com/poetas/espinola1.htm\#Sor\%20Juana\%20In\%C3\%A9s\%20de\%20la\%20Cruz

${ }^{2}$ Do poema Monocorde, 1976.

${ }^{3}$ Do poema Acorde segundo, 1976.

${ }^{4}$ Do poema Nacer mujer-poeta, 1985.

${ }^{5}$ Do poema Poesía, 1990.

${ }^{6}$ Do poema Hay máscaras y espejos, 1990.

${ }^{7}$ Ela afirma que esta foi uma grande entrada “por la puerta grande” (ESPÍNOLA, 2004, p. 618).

${ }^{8}$ Do poema Me desnudé entera, 2001.
}

\footnotetext{
${ }^{2}$ Em entrevista à Inês Braga da Universidade Fernando Pessoa em Portugal, ela assume que quer que sua obra permaneça, por acreditar que «a palavra sobrevive ao poeta» (Partidas y regresos, 1990).
} 
${ }^{9}$ Do poema El dolor es un mal pasajero, 1995.

Referências

ARGÜELLO, Miguel Ángel. Ocultaciones, omisiones y equívocos en la historia de la literatura paraguaya. Raído, Dourados, MS, v. 2, n. 3, p. 53-64, jan./jun. 2008.

BOSI, Alfredo. O ser e o tempo da poesia. São Paulo: Cultrix; Ed. USP, 1977.

CIRLOT, Juan-Eduardo. Dicionário de símbolos. São Paulo: Centauro, 2005.

ESPÍNOLA, Lourdes. Monocorde amarillo. Ocara Poty Cue Mí: Asunción, 1976.

. Ser mujer y otras desventuras/Womanhood and Other Misfortunes. EUA:

Latitudes Press, U.S.A., 1985.

La estrategia del caracol. Asunción: Arandurá Editorial, 1995.

. Encre de Femme/Tinta de Mujer. Paris: Indigo Editions, 1997.

Les Mots du Corps/Las Palabras del Cuerpo. Paris: Indigo Cote Femmes, 2001.

. Las palabras del cuerpo. BAY, Carmen Alemany; JUAN, Eva Maria Valero (Ed.). In:

CONGRESO INTERNACIONAL DEL CELCIRP, 9, Río de la Plata 29, 30. Actas...

Relaciones culturales y literarias entre los países del Río de la Plata. Universidad de Alicante, 2004. p. 605-620.

. As núpcias silenciosas. Seleção e tradução de Albano Martins. Vila Nova de Famalicão - PT : Edições Quasi, 2006.

Poesía de: Lourdes Espínola. Disponível em: <http://www.lospoetas.com/poetas/espinola1.htm\#Sor\%20Juana\%20In\%C3\%A9s\%20de\%20la\%20Cruz> Acesso em: 30 mar. 2010.

FERREIRA, Aurélio Buarque de H. Novo Dicionário Aurélio Digital. [S.l.] : Nova Fronteira, 1999.

PIZARRO, Mar Langa. La imagen del Paraguay a través de sus escritores. BAY, Carmen Alemany; JUAN, Eva Maria Valero (Ed.). CONGRESO INTERNACIONAL DEL

CELCIRP, 9, RÍO DE LA PLATa 29, 30. Actas del ... Relaciones culturales y literarias entre los países del Río de la Plata. Universidad de Alicante, 2004. p. 623-630 